\title{
CRIAÇÃO DE UM WEB SERVICE PARA O SISTEMA PATHOSPOTTER
}

\author{
Diogo Lima Marques ${ }^{1}$ e Angelo Amancio Duarte ${ }^{2}$ \\ 1. Bolsista PIBITI/CNPq, Graduando em Engenharia de Computação, Universidade Estadual de Feira de Santana, e- \\ mail: diogolimamarques@ @otmail.com \\ 2. Orientador, Departamento de Tecnologia, Universidade Estadual de Feira de Santana, e-mail: \\ angeloduarte@uefs.br
}

PALAVRAS-CHAVE: glomerulopatias, serviço web, telepatologia

\section{INTRODUÇÃO}

O projeto desenvolvido pelo bolsista representa os esforços conjuntos realizado pelo Laboratório de Computação de Alto Desempenho (LaCAD) da UEFS (Universidade Estadual de Feira de Santana) em parceria com a Fiocruz (Fundação Oswaldo Cruz) no desenvolvimento e manutenção do sistema PathoSpotter.

O termo patologia digital, ou telepatologia, "consiste na obtenção de imagens estáticas, dinâmicas ou híbridas, tanto macroscópicas quanto microscópicas, cujos fins são: o diagnóstico, a consulta e a educação médica e pesquisa”, Sartori et al. (2014).

Segundo a definição da SBN (Sociedade Brasileira de Nefrologia), as glomerulopatias [...] são doenças que acometem os glomérulos, estruturas constituídas por um tufo de capilares sanguíneos (delimitados por uma cápsula), além de uma série de outros elementos (entre eles, vários tipos de célula), responsáveis pela ultrafiltração do plasma. Podem ter origem nos rins e acometer apenas a esses órgãos (sendo, assim chamadas de glomerulopatias primárias) ou podem estar relacionadas a outras doenças, como diabetes e doenças auto-imunes.

O PhatoSpotter é um serviço capaz de identificar com precisão de mais de 80 (oitenta) por cento a incidência de lesões glomerulares a partir de imagens digitais. Tendo isso em vista, foi apontada a necessidade da disponibilização do PathoSpotter como um serviço: Um serviço web, capaz de permitir que seus usuários possam acessálo de forma simples e eficiente.

\section{METODOLOGIA}

O trabalho desenvolvido foi subdividido em três seções: Revisão bibliográfica, desenvolvimento do serviço web e a publicação dos resultados.

A revisão bibliográfica consistiu nos estudos e análise dos códigos referentes ao domínio do PathoSpotter, incluindo a compreensão da estrutura de arquivos de sites construídos em WordPress, compreensão de códigos em PHP, Javascript, Python e demais linguagens utilizadas nos códigos referentes ao serviço web, bem como o estudo das tecnologias a serem utilizadas, como os plugins escolhidos para a criação do serviço, o software de simulação de servidor do tipo Apache e a própria escolha da ferramenta WordPress para desenvolvimento da plataforma.

O desenvolvimento do serviço web consistiu no estudo dos códigos dos plugins escolhidos, de forma a alterar seu comportamento para que possibilitassem o uso do serviço da forma pretendida. Os códigos Python utilizados para análise de 
glomerulopatias em imagens digitais foram ligeiramente alterados para aceitar as necessárias entradas e saídas de dados do serviço. Os testes foram realizados utilizando imagens de glomérulos com resultados conhecidos, disponibilizadas pela Fiocruz.

A publicação dos resultados se deu na forma da criação de um domínio, atualmente hospedado no servidor PALMA, na UEFS. O domínio disponibiliza informações referentes ao serviço, bem como o seu uso para o público.

\section{RESULTADOS}

O website desenvolvido para a divulgação do serviço web do PathoSpotter (pathospotter.uefs.br), foi desenvolvido usando a plataforma WordPress, devido à sua simplicidade e a vasta gama de plugins disponíveis para uso, que permitiram a personalização do serviço para que se comportasse da forma pretendida. $O$ site encontra-se disponível em duas línguas: PT-BR (Português do Brasil) e EN-US (Inglês Americano).

\section{PathoSpotter}

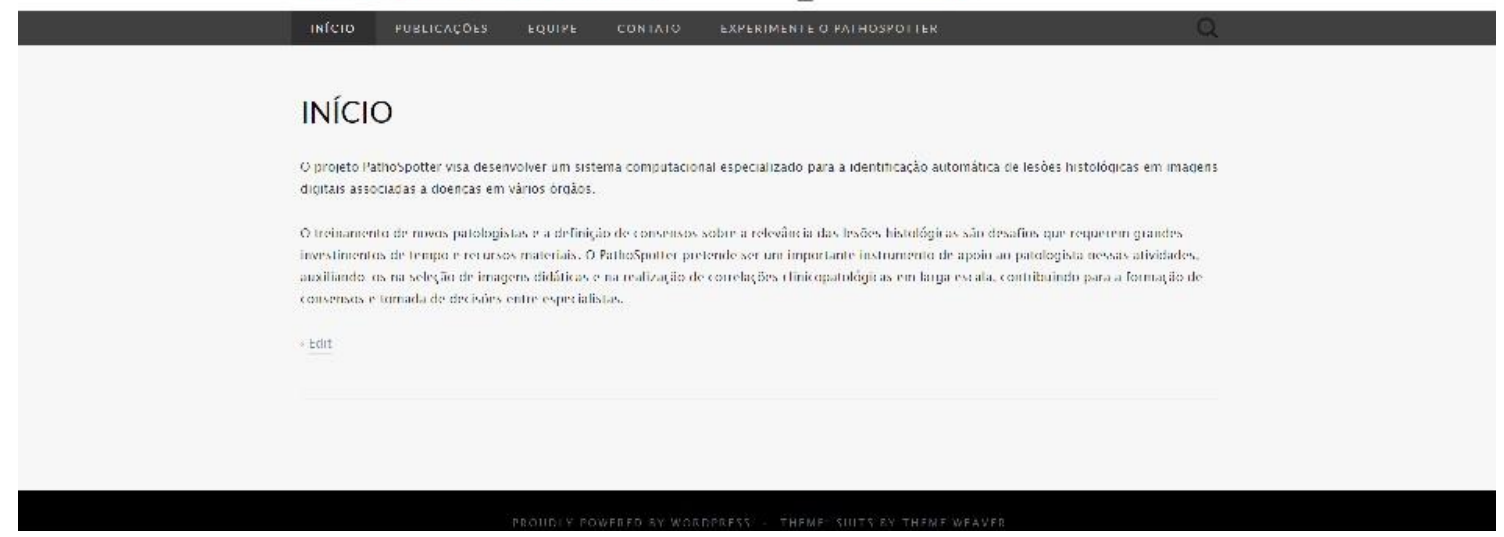

Figura 1: Página inicial do site do PathoSpotter, baseada no tema do WordPress: Suits.

Os plugins utilizados para a criação do serviço web foram: O WordPress File Upload e o PHP Code Snippets. Outros plugins secundários, como Polylang, para permitir a natureza bilíngue do site, também estão em execução no mesmo.

O serviço de análise de imagens de patologia digital se encontra na seção "Experimente o Pathospotter" do menu. Nela, o usuário pode fazer o upload de imagens de extensão .jpg, que serão submetidas ao código Python disponível no servidor e terão o resultado da análise devolvido para o console do browser do usuário. Tal operação acontece da seguinte forma: O plugin Wordpress File Upload permite que usuários façam subam arquivos para uma pasta personalizável pelo administrador. Utilizando snippets - isto é, recortes de código - de PHP, é possível fazer alterações no comportamento deste plugin. 


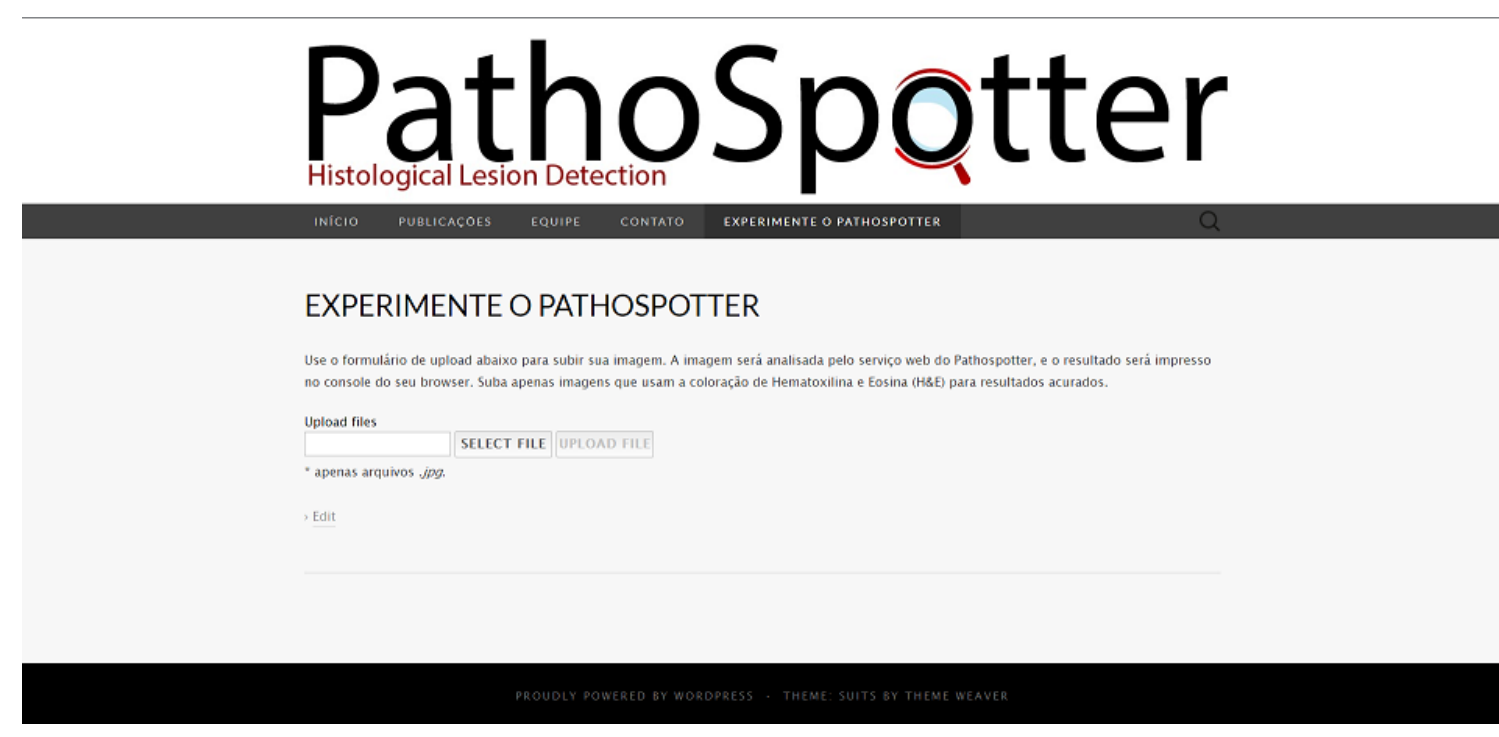

Figura 2: Página do PathoSpotter referente ao upload de imagens de patologia digital.

Dois snippets foram criados: Um para alterar o comportamento do código antes do upload ser realizado e outro para após o upload. O snippet responsável pelas alterações antes do upload fica responsável por alterar o caminho do arquivo carregado, bem como lhe dar um nome único e agregar metadados ao mesmo, como a data de upload e, se necessário, o nome do usuário que o fez. O segundo snippet fica encarregado de obter o novo caminho criado e encaminhá-lo para a execução do código Python de análise de patologia digital, obtendo o resultado e devolvendo-o para o usuário.

As imagens carregadas são disponibilizadas para os administradores do site no banco de imagens do mesmo. As imagens podem ser carregadas para diferentes diretórios, além do padrão do WordPress, de acordo com a necessidade dos administradores. Tais imagens, quando adquiridas em volume, podem ser utilizadas para futuros treinamentos do código Python, elevando sua acurácia à medida em que o serviço é mais utilizado.

\section{CONSIDERAÇÕES FINAIS}

Tendo em vista a característica do serviço PathoSpotter como um valioso serviço de patologia digital, acredita-se que ouve um avanço na disseminação de tecnologias do tipo, permitindo-se o uso da ferramenta para benefício da comunidade. Em troca, a obtenção de um banco continuamente crescente de imagens de patologia digital, das diferentes fontes das quais podem ser provenientes, fornecem para os mantenedores do serviço e de seus códigos uma fonte crescente de informação, que pode ser usada para a melhoria constante do serviço. Esta característica multilateral do serviço do PathoSpotter, se crê, é um dos aspectos mais chamativos de seus benefícios para a comunidade. 


\section{REFERÊNCIAS}

SARTORI, B.; HILlESHEIN, K.; RIBEIRO, O. 2014. Telepatologia. Anais de Medicina da Editora Unoesc. ISSN 2358-0984

CABRAL, A. 2018. O que são glomerulopatias?. Sociedade Brasileira de Nefrologia. Disponível em: <http://sbn.org.br/publico/doencas-comuns/glomerulopatias/> PIRES, M.; GARTNER, F.; TRAVASSOS, F. 2004. Atlas da Patologia Veterinária. Lidel. ISBN: 9789727572816 